\title{
THE REMOVAL OF LIPOPROTEIN LIPASE FROM THE BLOOD BY THE NORMAL AND DISEASED LIVER * $\dagger$
}

\author{
By WILLIAM E. CONNOR $\ddagger$ AND JOHN W. ECKSTEIN \\ From the Cardiovascular Research Laboratories, Department of Internal Medicine, State \\ University of Iowa College of Medicine, Iowa City, Ia.)
}

(Submitted for publication November 25, 1958; accepted June 19, 1959)

Lipoprotein lipase is an enzyme found in many organs and tissues. The highest concentration is in heart and adipose tissue $(2,3)$. Its unique physiological substrate consists of the triglyceride component of lipoproteins which it hydrolyzes to fatty acids and glycerol (4). Thus, it differs from pancreatic lipase which will act upon triglycerides not bound in a lipoprotein complex. Hahn first noted that this enzyme appeared in the blood in a highly active form following parenteral heparin administration. It had the property of reducing the turbidity of lipemic plasma (5) and became universally known as "clearing factor." Heparin or a heparin-like substance is now thought to be a part of the lipoprotein lipase molecule $(6,7)$.

Although the precise role of lipoprotein lipase in the metabolism of triglycerides has not yet been defined, it has excited great interest. It may play a role in the hydrolysis of chylomicron triglyceride formed after the ingestion of dietary fats. It may be involved in the pathogenesis of atherosclerosis. It may be important in the outflow of the unesterified fatty acids which provide a significant and readily mobilizable source of energy during the fasting state $(8,9)$.

Jeffries (10) and later Spitzer and Spitzer (11) showed that the isolated, perfused rat liver destroyed lipoprotein lipase. Jeffries also found that hepatic venous blood of the heparinized rat had less clearing activity than did aortic blood. Morris and French, however, were unable to demonstrate loss of clearing factor by perfusing the rat liver (12). Hepatectomized and cirrhotic rats had higher plasma lipemia clearing activity

\footnotetext{
* Presented at the annual meeting of the American Society for the Study of Arteriosclerosis in San Francisco, Calif. October 24, 1958 (1).

† Supported by research grants from the Iowa and American Heart Associations.

$\ddagger$ This work was performed during the tenure of an American Heart Association Research Fellowship.
}

than control rats (13). Baker, Levine, Turner and Dubin found that patients with hepatic cirrhosis had higher post-heparin blood levels of clearing factor than normal subjects (14). It was suggested that this increased activity might result from failure of the liver to inactivate the enzyme.

The present investigation was undertaken to define the role of the liver in the removal of lipoprotein lipase from the blood in dogs and humans. Lipoprotein lipase levels were determined in various vascular beds. In these species the normal liver removed lipoprotein lipase from the blood; liver disease prevented the usual removal.

\section{METHODS}

Animal experiments. Dogs in the fasting state, weighing from 17 to $25 \mathrm{Kg}$., were anesthetized with ether or sodium pentobarbital. Ten normal dogs were studied. Hepatic vein catheterization was performed via the external jugular vein. The catheter was placed in a branch of the hepatic vein draining the left lobe of the liver. A polyethylene catheter was introduced into a surgically exposed femoral vein for peripheral venous sampling. At the beginning of the experiment a preheparin sample was drawn from the femoral vein. Ten mg. of heparin ${ }^{1}$ was then given intravenously. The hepatic vein catheter was kept patent by a slow saline-heparin drip. Five mg. of additional heparin was given slowly by this route during the experiment. Simultaneous femoral and hepatic venous samples were drawn at 10,60 and 90 minutes post-heparin. Blood in $9 \mathrm{ml}$. amounts was added to $1 \mathrm{ml}$. of 1.85 per cent potassium oxalate solution in tubes chilled in an ice bath. Specimens were centrifuged at $4,000 \mathrm{rpm}$ and $4^{\circ} \mathrm{C}$. for 10 minutes. Subsequently, the plasma specimens were kept at $4^{\circ} \mathrm{C}$. for a period not longer than two hours before enzymatic activity was determined. The enzyme remains stable in plasma for at least 24 hours at $4^{\circ} \mathrm{C}$.

Hepatic necrosis was induced in three dogs by carbon tetrachloride or chloroform poisoning $(15,16)$. The same studies were performed as in the normal dogs. In Dogs 1 and 2 studies were performed before and after liver poisoning. All three dogs developed severe icterus,

\footnotetext{
${ }^{1}$ Sodium heparin, Abbott Laboratories.
} 
anorexia and vomiting. The experiments were performed on the third day of illness. Hepatic necrosis was confirmed by gross and microscopic examination in two dogs which died later in hepatic coma.

We have assumed in these studies that the lipoprotein lipase level in peripheral venous blood is similar to the level in blood entering the liver (i.e., in portal vein and hepatic artery blood). In four normal dogs this hypothesis was checked by obtaining post-heparin blood samples simultaneously from the portal vein, the femoral vein, the hepatic vein and the femoral artery. The portal vein was exposed after laparotomy. A Cournand needle was inserted into the femoral artery of these dogs for arterial blood sampling.

Human experiments. Ten human subjects were studied in the fasting state. All had been receiving the general hospital diet with regard to fat content and were eating well. Five, to be termed normals, had no evidence of liver disease. Four had mild hypertension and one had valvular heart disease. None was in cardiac failure. Five other subjects had long-standing Laennec's cirrhosis documented by physical examination, very abnormal liver function tests, and liver biopsy. Ascites, present in three patients, did not influence the results of this study. The cirrhotic patients were in good nutritional state. All had hepatic vein wedge pressures elevated to at least $20 \mathrm{~mm}$. of mercury. Hepatic vein catheterization was performed by introducing a catheter into an antecubital vein and under fluoroscopic control passing it through the right atrium and inferior vena cava into a branch of the hepatic vein draining the right lobe of the liver. A Cournand needle was inserted into the other antecubital vein and in some experiments into the femoral artery. At the beginning of the experiment a preheparin sample was drawn from the antecubital vein. After the catheter was put into position in the free hepatic vein, $10 \mathrm{mg}$. of heparin was given intravenously. Simultaneous antecubital and hepatic venous samples were drawn at 10,60 , and occasionally 90 minutes postheparin. Femoral arterial samples were also obtained in several subjects. Blood was handled as in the dog experiments.

Lipoprotein lipase activity. Plasma lipoprotein lipase was quantified in two ways: (a) by the reduction in optical density or "clearing" of a plasma-coconut oil emulsion and $(b)$ by the measurement of glycerol produced by lipolytic action. These techniques were modified from descriptions by Grossman (17), Korn (2) and Baker (18). Coconut oil provides a suitable substrate for lipoprotein lipase despite the inability of the enzyme to act upon purified triglycerides. As Korn has demonstrated (4), the incubation of coconut oil with plasma lipoproteins results in the formation of a complex analogous to chylomicrons with respect to lipoprotein lipase action.

Plasma was warmed at $37^{\circ} \mathrm{C}$. for three minutes. Then $2.5 \mathrm{ml}$. was mixed with $0.3 \mathrm{ml}$. of a coconut oil emulsion. ${ }^{2}$

${ }^{2}$ Ediol, Schendley Laboratories; kindly provided by Dr. B. M. Lamman.
The concentration of the emulsion was adjusted so that the mixture of plasma and coconut oil gave an initial optical density reading of approximately 0.60 unit. The optical density and glycerol content of the plasmacoconut oil emulsion were determined in duplicate at zero time and after 120 minutes of incubation at $37^{\circ} \mathrm{C}$. The 120 minute incubation period was selected as a suitable time for the measurement of both optical density change and glycerol production in the same incubation tube. We had found glycerol production still linear at 120 minutes. The change in optical density was linear for the lower levels of lipoprotein lipase usually found in 60 and 90 minute post-heparin specimens. The 120 minute period was long enough so that the low levels of lipoprotein lipase present in some plasma specimens could be determined. Bovine albumin was not added to the incubation system because we did not wish to mask a possible effect of the altered plasma proteins of liver disease upon lipoprotein lipase activity. Since oxalated plasma was employed, the formation of turbid calcium soaps was not a problem. In no instance did the incubation tube develop more turbidity after maximal clearing had occurred. Anfinsen's data had indicated a similar lack of returbidification after 180 minutes of incubation (19). Korn had used a 120 minute incubation period for many of his experiments employing lipoprotein lipase from rat heart (2).

The optical density was read in $10 \mathrm{~mm}$. cuvettes at a wave length of $650 \mathrm{~m} \mu$ in a Coleman Junior Spectrophotometer. For glycerol determinations $0.5 \mathrm{ml}$. aliquots of the plasma-coconut oil emulsion were added to chilled tubes containing $0.1 \mathrm{ml}$. of $0.1 \mathrm{~N}$ sulfuric acid. The plasma proteins were precipitated by $2 \mathrm{ml}$. of 20 per cent trichloroacetic acid. Glycerol was determined on $0.25 \mathrm{ml}$. of the filtrate by the method of Lambert and Neish (20) and expressed in $\mu$ Mole per $\mathrm{ml}$. The results were analyzed statistically by the methods of Fisher (21).

\section{Normal dogs}

RESULTS

Ten healthy mongrel dogs had much higher levels of lipoprotein lipase in peripheral vein blood than in hepatic vein blood 60 and 90 minutes postheparin. The data for each dog at 10,60 and 90 minutes post-heparin are tabulated in Table I. No significant differences occurred at the $10 \mathrm{~min}-$ ute period for the group, but Dog 9 had considerable 10 minute peripheral vein-hepatic vein differences. These were 0.230 optical density unit and $0.54 \mu$ Mole of glycerol.

At 60 minutes the optical density change for all normal dogs averaged 0.304 unit in the peripheral vein samples and 0.213 unit in the hepatic vein samples. The mean difference was 0.091 $(\mathrm{p}<0.001)$. Glycerol production in these ani- 
WILLIAM E. CONNOR AND JOHN W. ECKSTEIN

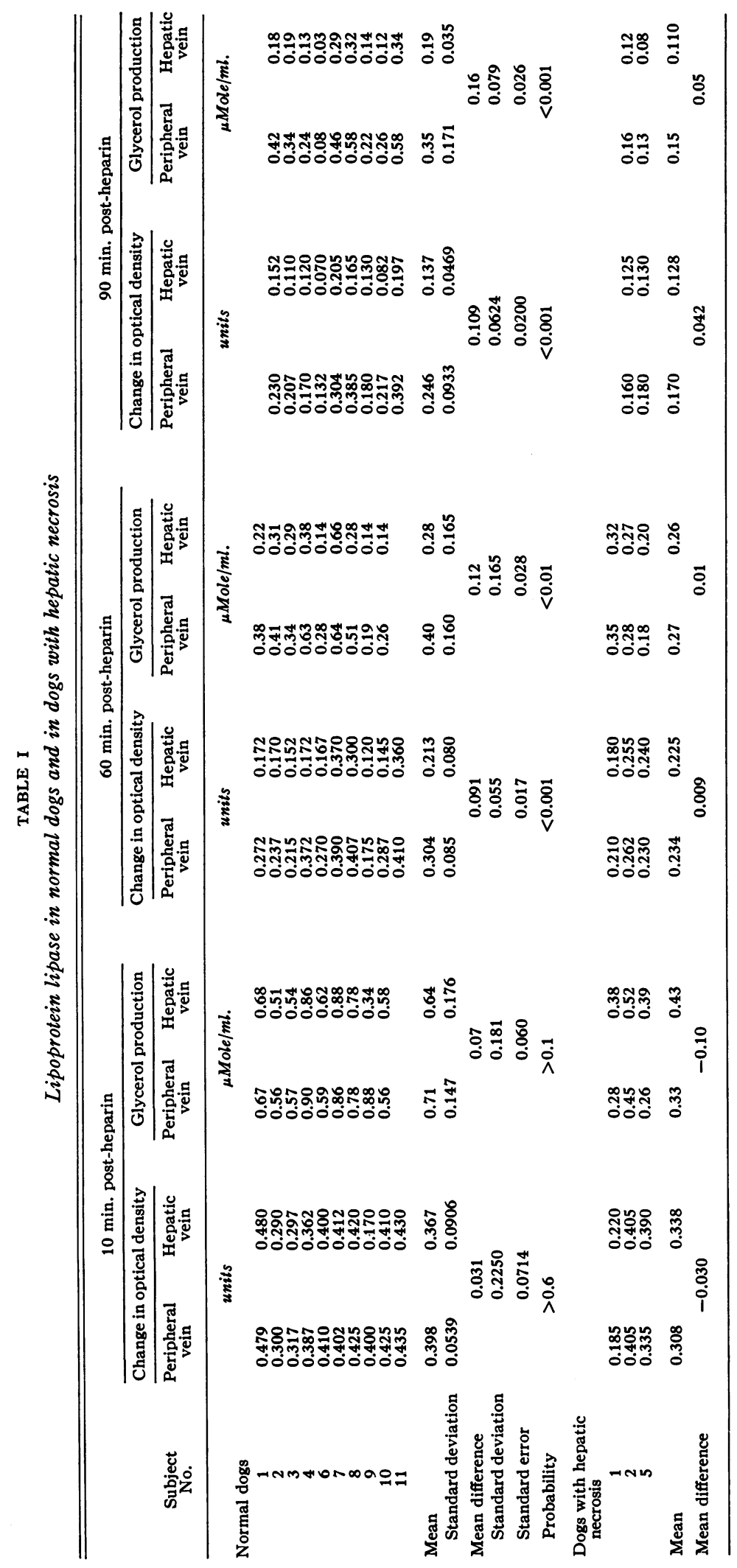


TABLE II

Lipoprotein lipase levels in four vascular beds in normal dogs

\begin{tabular}{|c|c|c|c|c|c|c|c|c|c|}
\hline \multicolumn{2}{|c|}{ Normal dogs } & \multicolumn{4}{|c|}{ Change in optical density } & \multicolumn{4}{|c|}{ Glycerol production } \\
\hline $\begin{array}{l}\text { Subject } \\
\text { No. }\end{array}$ & $\begin{array}{l}\text { Post-heparin } \\
\text { sampling time }\end{array}$ & $\begin{array}{c}\text { Femoral } \\
\text { vein }\end{array}$ & $\begin{array}{c}\text { Femoral } \\
\text { artery }\end{array}$ & $\begin{array}{c}\text { Portal } \\
\text { vein }\end{array}$ & $\underset{\text { vein }}{\text { Hepatic }}$ & $\underset{\text { vein }}{\text { Femoral }}$ & $\begin{array}{c}\text { Femoral } \\
\text { artery }\end{array}$ & $\begin{array}{c}\text { Portal } \\
\text { vein }\end{array}$ & $\begin{array}{c}\text { Hepatic } \\
\text { vein }\end{array}$ \\
\hline & $\min$. & \multicolumn{4}{|c|}{ units } & \multicolumn{4}{|c|}{ MMole/ml. } \\
\hline 8 & $\begin{array}{l}10 \\
60 \\
90\end{array}$ & $\begin{array}{l}0.425 \\
0.407 \\
0.385\end{array}$ & $\begin{array}{l}0.440 \\
0.300 \\
0.320\end{array}$ & $\begin{array}{l}0.430 \\
0.345 \\
0.350\end{array}$ & $\begin{array}{l}0.420 \\
0.140 \\
0.165\end{array}$ & $\begin{array}{l}0.78 \\
0.51 \\
0.58\end{array}$ & $\begin{array}{l}0.74 \\
0.48 \\
0.48\end{array}$ & $\begin{array}{l}0.72 \\
0.49 \\
0.50\end{array}$ & $\begin{array}{l}0.78 \\
0.28 \\
0.32\end{array}$ \\
\hline 9 & $\begin{array}{l}10 \\
60 \\
90\end{array}$ & $\begin{array}{l}0.400 \\
0.175 \\
0.180\end{array}$ & $\begin{array}{l}0.320 \\
0.125 \\
0.140\end{array}$ & $\begin{array}{l}0.370 \\
0.155 \\
0.170\end{array}$ & $\begin{array}{l}0.170 \\
0.120 \\
0.130\end{array}$ & $\begin{array}{l}0.88 \\
0.19 \\
0.22\end{array}$ & $\begin{array}{l}0.62 \\
0.24\end{array}$ & $\begin{array}{l}0.64 \\
0.16 \\
0.16\end{array}$ & $\begin{array}{l}0.34 \\
0.14 \\
0.14\end{array}$ \\
\hline 10 & $\begin{array}{l}10 \\
60 \\
90\end{array}$ & $\begin{array}{l}0.425 \\
0.225 \\
0.147\end{array}$ & $\begin{array}{l}0.420 \\
0.170 \\
0.117\end{array}$ & $\begin{array}{l}0.425 \\
0.225 \\
0.147\end{array}$ & $\begin{array}{l}0.410 \\
0.145 \\
0.082\end{array}$ & $\begin{array}{l}0.56 \\
0.26 \\
0.26\end{array}$ & $\begin{array}{l}0.60 \\
0.22 \\
0.18\end{array}$ & $\begin{array}{l}0.54 \\
0.20 \\
0.22\end{array}$ & $\begin{array}{l}0.58 \\
0.14 \\
0.12\end{array}$ \\
\hline 11 & $\begin{array}{l}10 \\
60 \\
90\end{array}$ & $\begin{array}{l}0.435 \\
0.410 \\
0.380\end{array}$ & $\begin{array}{l}0.430 \\
0.410 \\
0.380\end{array}$ & $\begin{array}{l}0.430 \\
0.420 \\
0.392\end{array}$ & $\begin{array}{l}0.430 \\
0.360 \\
0.197\end{array}$ & 0.58 & 0.58 & 0.58 & 0.34 \\
\hline $\begin{array}{l}\text { Means for each } \\
\text { vascular bed }\end{array}$ & $\begin{array}{l}10 \\
60 \\
90\end{array}$ & $\begin{array}{l}0.421 \\
0.306 \\
0.273\end{array}$ & $\begin{array}{l}0.403 \\
0.251 \\
0.239\end{array}$ & $\begin{array}{l}0.414 \\
0.289 \\
0.263\end{array}$ & $\begin{array}{l}0.357 \\
0.191 \\
0.169\end{array}$ & $\begin{array}{l}0.74 \\
0.32 \\
0.41\end{array}$ & $\begin{array}{l}0.65 \\
0.31 \\
0.41\end{array}$ & $\begin{array}{l}0.63 \\
0.28 \\
0.37\end{array}$ & $\begin{array}{l}0.57 \\
0.19 \\
0.31\end{array}$ \\
\hline
\end{tabular}

mals was found to be $0.40 \mu$ Mole in peripheral vein and $0.28 \mu$ Mole in hepatic vein samples. The mean difference was $0.12 \mu \mathrm{Mole}$, also significant $(\mathrm{p}<0.01)$.

Similar results occurred at 90 minutes postheparin. The optical density difference was 0.109 unit $(p<0.001)$ and the glycerol difference between peripheral and hepatic vein samples was $0.16 \mu$ Mole $(p<0.001)$. In one dog $10 \mathrm{mg}$. of intravenous protamine ${ }^{3}$ caused a prompt reduction of lipoprotein lipase activity in both vascular beds. The experimental results with the use of either Nembutal ${ }^{\circledR}$ or ether were similar.

Comparison of lipoprotein lipase in the femoral vein, femoral artery, portal vein and hepatic vein in normal dogs. The question arose: Does the significant difference in the lipoprotein lipase levels of peripheral and hepatic vein blood indicate that the liver removes this enzyme from the blood? The answer could only be in the affirmative if lipoprotein lipase in peripheral vein blood was shown to be equivalent to the level in the blood entering the liver, i.e., by the portal vein and hepatic artery. Such an assumption has appeared true for Bromsulphalein ${ }^{\circledR}$ levels (22). Peripheral vein-hepatic vein differences could mean removal of the enzyme by the lungs, intestinal tract, spleen or kidneys as well as by the liver. These possibili-

\footnotetext{
3 Protamine sulfate, Eli Lilly and Co.
}

ties were investigated in four normal dogs by determining simultaneous lipoprotein lipase levels in the femoral, portal and hepatic veins and the femoral artery. Since hepatic and femoral arterial blood are identical, this experiment permitted a comparison of all blood entering the liver with the blood leaving the liver. Enzymatic activity in blood from these vascular beds and from peripheral venous blood can also be related. As shown in Table II both the optical density change and glycerol production values were much lower in the hepatic vein than in any of the three other vascular beds. At 60 minutes post-heparin, hepatic vein optical density change averaged 0.191 unit as compared with 0.306 unit in the femoral vein, 0.251 unit in the femoral artery and 0.289 unit in the portal vein. The glycerol values from the femoral artery, the femoral vein and the portal vein were grouped together, from 0.32 to $0.28 \mu \mathrm{Mole}$. These were clearly different from the hepatic vein glycerol production of $0.19 \mu$ Mole. At 90 minutes post-heparin the data show the same grouping. At 10 minutes post-heparin, as also occurred in the group of normal dogs (Table I), no great differences occurred between any of the vascular beds except for Dog 9 which did have marked differences. In this instance, too, femoral vein, femoral artery and portal vein values were grouped together in contrast to much lower hepatic vein 


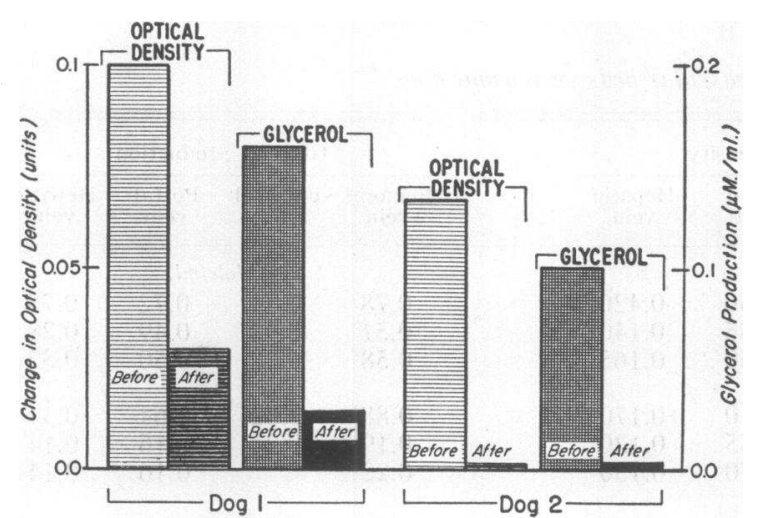

Fig. 1. Hepatic Removal of Lipoprotein Lipase in Two Dogs Before and After Development of Acute Hepatic Necrosis

The peripheral vein-hepatic vein differences for optical density change and glycerol production are given for 60 minute post-heparin specimens.

values for both optical density change and glycerol production. These data fortify the assumption that the lipoprotein lipase level in peripheral vein blood (femoral or antecubital) is representative of the level in the blood entering the liver.

While the lipoprotein lipase levels in the femoral vein and femoral artery are similar, slight

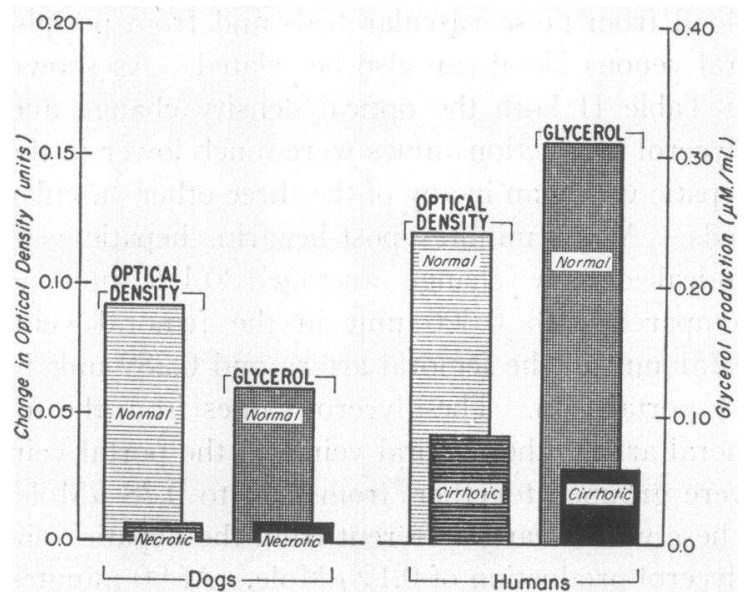

Fig. 2. Hepatic Removal of Lipoprotein Lipase in Dogs and Humans

Each vertical bar represents the peripheral veinhepatic vein difference in lipoprotein lipase activity as measured by optical density change and glycerol production. The normal liver is contrasted with the diseased liver in humans having Laennec's cirrhosis and in dogs with acute hepatic necrosis. All values are those obtained 60 minutes post-heparin. differences are apparent in Dogs 8, 9 and 10, but not in Dog 11. Dog 8 at 60 minutes post-heparin had a femoral vein-femoral artery difference of 0.107 optical density unit and $0.03 \mu$ Mole of glycerol; at 90 minutes differences were 0.065 optical density unit and $0.10 \mu$ Mole of glycerol. Dog 9 had greatest peripheral venous-arterial differences at the 10 minute time. Dog 10 had differences at 60 and 90 minutes.

\section{Dogs with hepatic necrosis}

Acute liver poisoning with chloroform or carbon tetrachloride greatly reduced the hepatic removal of lipoprotein lipase. At the 10 minute postheparin time there was a negative peripheral veinhepatic vein difference of both optical density change and glycerol production (Table I). At 60 minutes post-heparin, the optical density change of the peripheral vein plasma averaged 0.234 optical density unit as compared with the 0.225 unit of hepatic vein plasma. The two vascular beds had also similar glycerol values. At 90 minutes post-heparin there was again little lipoprotein lipase removal by the necrotic liver.

Twa dogs, 1 and 2, were studied before and after the induction of acute hepatic necrosis. Figure 1 shows that the normal liver of each dog removed lipoprotein lipase as indicated by peripheral vein-hepatic vein differences in optical density change and glycerol production. After hepatic necrosis there was a great diminution in lipoprotein lipase removal.

A comparison of lipoprotein lipase removal for all dogs indicates greater removal by the normal than by the necrotic liver. Figure 2 compares the mean lipoprotein lipase removal for normal dogs and dogs with hepatic necrosis at 60 minutes post-heparin. The normal dogs had a peripheral vein-hepatic vein difference of 0.091 optical density unit; the dogs with hepatic necrosis had a difference of only 0.009 (one-tenth as much). The normal dogs had a difference of $0.12 \mu \mathrm{Mole}$ of glycerol as compared with only a difference of $0.01 \mu$ Mole in the dogs with hepatic necrosis. At 90 minutes post-heparin the normal dogs removed 0.109 optical density unit versus a removal of only 0.042 unit for dogs with hepatic necrosis. In terms of glycerol the normal liver removed 0.16 $\mu$ Mole and the necrotic liver only $0.05 \mu$ Mole. 
HEPATIC REMOVAL OF LIPOPROTEIN LIPASE FROM THE BLOOD

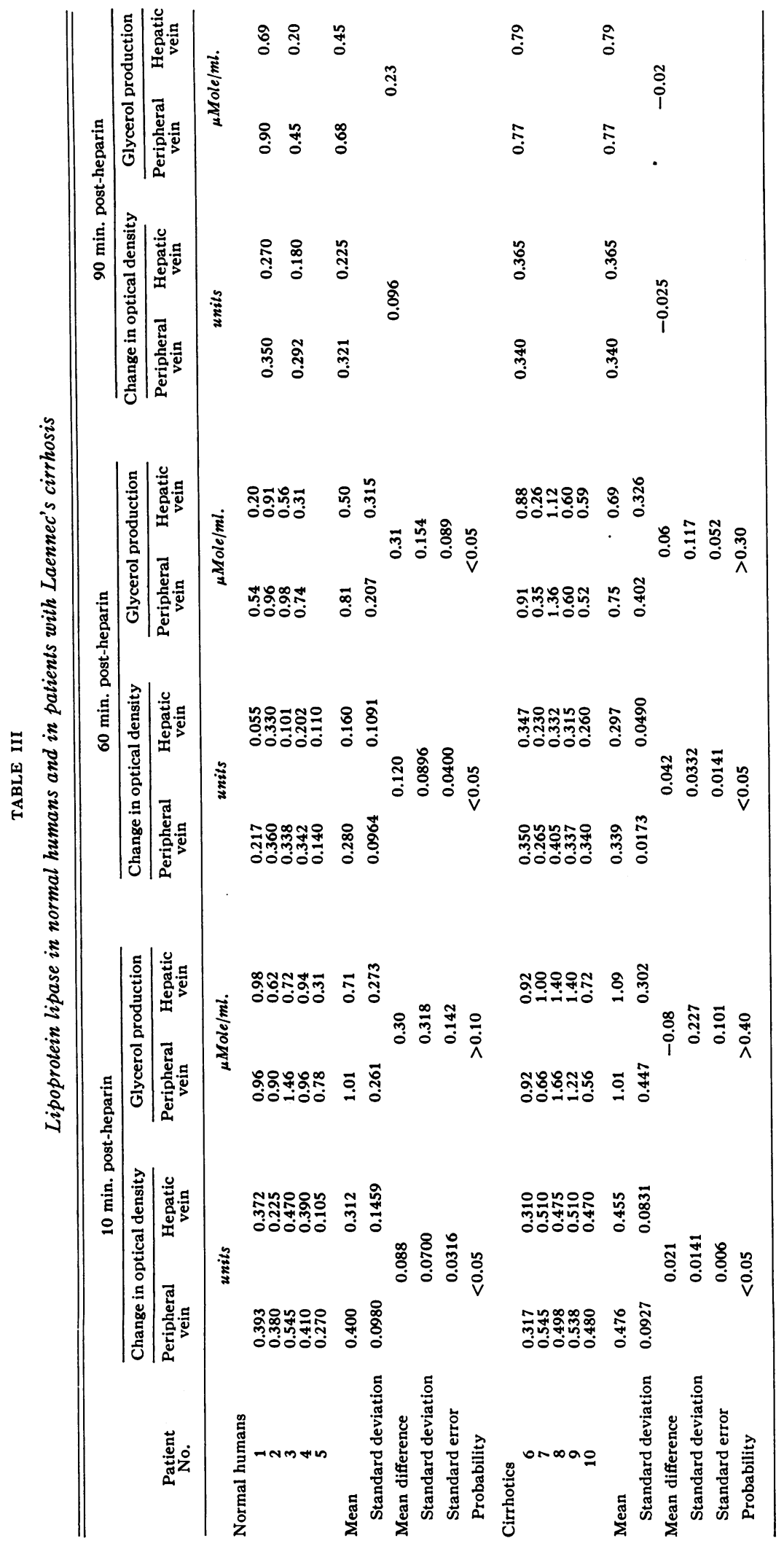




\section{Human subjects}

Results in five normal human subjects are tabulated individually in Table III. Subjects 2 and 5 had the greatest peripheral vein-hepatic vein differences for both optical density and glycerol at 10 minutes post-heparin, while Subjects 1,3 and 4 developed greatest differences at 60 minutes post-heparin. These peak differences ranged between 0.140 to 0.237 optical density unit and between 0.28 to $0.47 \mu$ Mole of glycerol. When the data from all five normal subjects are considered for the 60 minute post-heparin time, the mean differences were 0.120 optical density unit and $0.31 \mu$ Mole of glycerol. These were both significant $(p<0.05)$. The mean differences for all subjects at 10 minutes post-heparin were 0.087 optical density unit and $0.30 . \mu$ Mole of glycerol. The two subjects, 2 and 4, studied at 90 minutes post-heparin both showed lipoprotein lipase removal by the liver. Their mean differences were 0.096 optical density unit and $0.23 \mu$ Mole of glycerol.

The five patients with Laennec's cirrhosis had less clear cut peripheral vein-hepatic vein differences (Table III). Differences were especially minimal as regards glycerol production. The peak difference for each patient occurred at 60 minutes post-heparin and ranged from 0.003 to 0.08 optical density unit and from 0 to 0.24 $\mu$ Mole of glycerol. The mean differences were 0.042 optical density unit and $0.06 \mu$ Mole of glycerol. The differences at 10 and 90 minutes post-heparin were much less. The one patient studied at 90 minutes had negative differences. The intravenous injection of $10 \mathrm{mg}$. of protamine in two patients caused the lipoprotein lipase levels in peripheral and hepatic veins to fall to the preheparin levels within 10 minutes.

When the hepatic removal of lipoprotein lipase was compared in normal and cirrhotic subjects, the normal liver removed more lipoprotein lipase (Figure 2). At 10 minutes post-heparin the standard error of the mean differences (normals as opposed to cirrhotics) was 0.0565 optical density unit $(p>0.05)$ and $0.309 \mu$ Mole of glycerol $(p>0.05)$. At 60 minutes the standard error was 0.075 optical density unit $(p>0.1)$ and $0.152 \mu$ Mole of glycerol $(\mathrm{p}<0.05)$.

In two normal humans and in two cirrhotic pa- tients the lipoprotein lipase level was higher at 60 minutes post-heparin in the perhipheral vein than in the peripheral artery. The two normal subjects had 15 and 12 per cent higher optical density values in venous samples; the two cirrhotics had 9 and 7 per cent higher values in venous samples. At 10 minutes post-heparin the normal subjects had 5 and 25 per cent higher venous values, but the cirrhotics had no peripheral venous-arterial difference at this time. In terms of glycerol, there were similar venous-arterial differences for the four subjects.

\section{DISCUSSION}

These results indicate that the normal liver removes lipoprotein lipase from the blood in both dogs and humans. Another interpretation of the data might be that the liver adds a substance to hepatic vein blood which inhibits the action of lipoprotein lipase. No information is available on this question. The hepatic removal may be regarded as an extraction or denaturation phenomenon in which the lipoprotein lipase content of blood entering the liver is related to the content in blood leaving the liver. The close similarity of the levels of enzyme in peripheral vein blood and in blood entering the liver has been demonstrated. Lipoprotein lipase has been quantified by the change in the optical density of the plasmacoconut oil emulsion which occurred as particle size was reduced and by the production of glycerol from hydrolysis of lipoprotein triglycerides. Both methods of measurement, the optical and the chemical, yielded data supporting the same conclusion about hepatic removal of lipoprotein lipase. A double check on the data was thus obtained. A third technique of measurement, used by others (23), has been the determination of fatty acids formed by enzymatic activity.

If the normal liver removes lipoprotein lipase, then the diseased liver might well have a reduction of this function. Such has been the case in human cirrhosis and in dogs with acute hepatic necrosis. The differences across the liver for optical density change and glycerol production were reduced strikingly. The failure of the diseased liver to perform as did the normal liver provided further evidence of hepatic removal of lipoprotein lipase from the blood. Two reasons 
may be advanced for the reduced removal of the enzyme in liver disease. First, hepatocellular damage might prevent a normal function of the liver; second, it is known that anastomoses develop between the portal and hepatic veins in cirrhosis and following hepatic necrosis (24). Such shunts would greatly reduce the usual flow of blood reaching hepatic cells and thus cause an overall impairment of hepatic function.

Previous work on this subject has been done only with the rat, an animal whose liver is said not to contain heparin or mast cells (25). Jeffries (10) and Spitzer and Spitzer (11) found that the isolated perfused rat liver destroyed clearing factor. This was not confirmed by Morris and French who employed a similar preparation (12). We suggest a possible explanation for this one divergent experimental report. The amount of plasma lipoprotein lipase with which the liver is presented may be a critical factor in the determination of hepatic removal by perfusion or sampling techniques. The time of sampling may be another factor. We routinely sampled at several different times after the administration of heparin-at 10,60 and usually 90 minutes. Heparin effect was maximal at 10 minutes, as indicated by prolonged whole blood clotting times and high levels of lipoprotein lipase. Differences between peripheral vein and hepatic vein levels were then less significant. We might ascribe this lack of difference to the possible overloading of the liver by large amounts of the enzyme. This effect might be expected soon after heparin injection when circulating blood levels of heparin were high and continuing to stimulate the entry of lipoprotein lipase into the blood. For most of the human subjects and for nine dogs the sample times giving the greatest differences were at 60 and 90 minutes when the whole blood clotting times were lower or even normal and overall lipoprotein lipase levels were somewhat lower.

Recently, Robinson and Harris have shown that after a single passage of blood containing heparin through the rabbit hind limb that lipoprotein lipase activity can be detected in the venous return (26). Such a rapid release suggested to them that a lipolytic enzyme was probably derived from the inner lining of blood vessel walls. This work substantiates another report, that the peripheral tissues in the rat release lipoprotein lipase into the blood (10). In humans and in dogs this same enzymatic release by the peripheral tissues appears to occur. We found higher levels of lipoprotein lipase in peripheral venous than in peripheral arterial blood. The high content of lipoprotein lipase in adipose tissue (3) may mean that this tissue or its capillaries supplied at least some of the lipoprotein lipase appearing in the blood after heparin.

The physiological significance of hepatic removal of lipoprotein lipase is uncertain. The enzyme may possibly be destroyed in the liver by heparinase, known to be present in the livers of some species (27). The incubation of lipoprotein lipase with heparinase from liver (11), with a bacterial heparinase (6) and with a liver tissue homogenate (28) all caused a great reduction of enzymatic activity. A recent study demonstrated that injected heparin is inactivated by the liver (29). Heparin or a heparin-like substance appears to be an integral part of the lipoprotein lipase molecule. When heparin was removed from it by passage through an anion exchange resin, enzymatic activity disappeared (30). It could be restored by the addition of heparin. Other evidence indicates that lipoprotein lipase represents a combination of heparin and apo-enzyme from which heparin is dissociated readily (31). Adding further to the idea of the close relationship of heparin and lipoprotein lipase is the often repeated observation that heparin antagonists block the action of the enzyme both in vitro and in vivo. The prompt decline of lipoprotein lipase levels in the blood following intravenous protamine in our experiments illustrates this antagonism.

Much of the current interest in lipoprotein lipase relates to its possible role in atherosclerosis. It has been suggested that alimentary hyperlipemia or chylomicronemia may be an etiological factor in the development of this disease (32). The delayed clearing of dietary triglycerides in patients with coronary atherosclerosis $(33,34)$ provides evidence of a possible lipoprotein lipase deficiency in such individuals. Block, Mann and Barker have shown that a small dose of intravenous heparin produced less clearing of the lipemia induced by a fatty meal in coronary patients than in normal persons (35). Others have found that plasma 
from atherosclerotic individuals was inhibitory to clearing activity $(36,37)$. It has been shown, also, that the cofactor activity in the lipoprotein lipase system is reduced in atherosclerotic patients (38).

Patients with cirrhosis of the liver appear to have accelerated clearing of triglycerides from the blood (39) and exhibit very high levels of clearing factor after the injection of heparin (14). Our studies in cirrhotic patients and in dogs with hepatic necrosis suggest that such phenomena may occur because of the reduced removal of lipoprotein lipase from the blood in liver disease. The pathological and clinical evidence indicates that patients with cirrhosis of the liver have less atherosclerosis and myocardial infarction than comparable groups of patients dying from other causes (40-42). One may then pose the question: Might the decreased hepatic removal of lipoprotein lipase in cirrhosis contribute to a lessened incidence of atherosclerosis? The hyperestrogenism, absence of hypertension, hypocholesterolemia, poor nutrition, hypoprothrombinemia, and increased fibrinolysis, all occurring at times in advanced cirrhosis, might be additional contributing factors.

\section{SUMMARY}

1. The lipoprotein lipase content of plasma after the administration of heparin was compared in blood collected simultaneously from the peripheral and hepatic veins. In five normal human subjects and in 10 normal dogs the liver removed or inactivated significant amounts of the lipoprotein lipase with which it was presented.

2. Impairment of liver function greatly reduced the hepatic removal of the enzyme. This was shown in five human patients with Laennec's cirrhosis of the liver and in three dogs with acute hepatic necrosis.

3. In four normal dogs the lipoprotein lipase level in the blood entering the liver was similar to the peripheral venous level and different from the hepatic venous level. On the basis of these data hepatic removal of the enzyme could be determined from peripheral and hepatic venous blood.

4. Lipoprotein lipase was measured in peripheral venous and arterial blood in four normal dogs and in four humans. The differences between peripheral venous and arterial blood were consistent with the release of lipoprotein lipase into the peripheral tissues.

\section{REFERENCES}

1. Connor, W. E., and Eckstein, J. W. The removal of lipoprotein lipase from the blood by the normal and diseased liver (abstract). Circulation 1958, 18, 483.

2. Korn, E. D. Clearing factor, a heparin-activated lipoprotein lipase. I. Isolation and characterization of the enzyme from the normal rat heart. J. biol. Chem. 1955, 215, 1.

3. Korn, E. D., and Quigley, T. W., Jr. Lipoprotein lipase of chicken adipose tissue. J. biol. Chem. 1957, 226, 833.

4. Korn, E. D. Clearing factor, a heparin-activated lipoprotein lipase. II. Substrate specificity and activation of coconut oil. J. biol. Chem. 1955, 215, 15.

5. Hahn, P. F. Abolishment of alimentary lipemia following injection of heparin. Science 1943, 98, 19.

6. Korn, E. D. Inactivation of lipoprotein lipase by heparinase. J. biol. Chem. 1957, 226, 827.

7. Anfinsen, C. B., Boyle, E., and Brown, R. K. The role of heparin in lipoprotein metabolism. Science 1952, 115, 583.

8. Dole, V. P. A relation between non-esterified fatty acids in plasma and the metabolism of glucose. J. clin. Invest. 1956, 35, 150.

9. Gordon, R. S., Jr., and Cherkes, A. Unesterified fatty acid in human blood plasma. J. clin. Invest. 1956, 35, 206.

10. Jeffries, G. H. Sites at which plasma clearing factor is produced and destroyed in the rat. Quart. J. exp. Physiol. 1954, 39, 261.

11. Spitzer, J. A., and Spitzer, J. J. Effect of liver on lipolysis by normal and postheparin sera in the rat. Amer. J. Physiol. 1956, 185, 18.

12. Morris, B., and French, J. E. The uptake and metabolism of ${ }^{14} \mathrm{C}$ labelled chylomicron fat by the isolated perfused liver of the rat. Quart. J. exp. Physiol. 1958, 43, 180.

13. Constantinides, P., So, Y., and Johnstone, F. R. C. Role of liver and kidney in development of heparininduced lipemia clearing activity (LCA). Proc. Soc. exp. Biol. (N. Y.) 1959, 100, 262.

14. Baker, S. P., Levine, H., Turner, L., and Dubin, A. Lipoprotein lipase response in Laennec's cirrhosis. Proc. Soc. exp. Biol. (N. Y.) 1958, 99, 670.

15. Leduc, E. H., and Wilson, J. W. Injury to liver cells in carbon tetrachloride poisoning. Arch. Path. (Chicago) 1958, 65, 147.

16. Carter, J. R., Chambers, G. H., and Warner, E. D. Effect on prothrombin of acute massive plasmapheresis with simultaneous chloroform intoxication. Proc. Soc. exp. Biol. (N. Y.) 1949, 72, 52.

17. Grossman, M. I. The quantitative measurement of 
heparin-induced lipemia clearing activity of plasma. J. Lab. clin. Med. 1954, 43, 445.

18. Baker, S. P. Heparin-activated clearing factor. Standardized test, agewise application, and clinical observations. Circulation 1957, 15, 889.

19. Anfinsen, C. B. Physiological aspects of lipid transport in Symposium on Atherosclerosis, Nat. Acad. Sci.-Nat. Res. Council, Div. Med. Sci., Washington, D. C., 1954 (Pub. 338), p. 217.

20. Lambert, M., and Neish, A. C. Rapid method for estimation of glycerol in fermentation solutions. Canad. J. Res. 1950, 28, 83.

21. Fisher, R. A. Statistical Methods for Research Workers, 10th ed. Edinburgh, Oliver and Boyd, Ltd., 1946.

22. Bradley, S. E., Ingelfinger, F. J., Bradley, G. P., and Curry, J. J. The estimation of hepatic blood flow in man. J. clin. Invest. 1945, 24, 890.

23. Shore, B., Nichols, A. V., and Freeman, N. K. Evidence for lipolytic action of human plasma obtained after intravenous administration of heparin. Proc. Soc. exp. Biol. (N. Y.) 1953, 83, 216.

24. Popper, H., and Schaffner, F. Liver: Structure and Function. New York, McGraw-Hill Book Company, Inc., 1957, p. 277.

25. Jorpes, J. E. Heparin in the Treatment of Thrombosis. An Account of its Chemistry, Physiology and Application in Medicine, 2nd ed. London, Oxford Univ. Press, 1946, p. 62.

26. Robinson, D. S., and Harris, P. M. The production of lipolytic activity in the circulation of the hind limb in response to heparin. Quart. J. exp. Physiol. 1959, 44, 80.

27. Cho, M. H., and Jacques, L. B. Heparinase. III. Preparation and properties of the enzyme. Canad. J. Biochem. 1956, 34, 799.

28. Klein, E., Lever, W. F., and Fekete, L. L. Inhibitors of lipemia clearing in tissues. J. invest. Derm. 1958, 30, 41.

29. Eiber, H. B., and Danishefsky, I. Synthesis and metabolism of radioactive heparin. Arch. intern. Med. 1958, 102, 189.

30. Robinson, D. S. Further studies on the lipolytic system induced in plasma by heparin injection. Quart. J. exp. Physiol. 1956, 41, 195.

31. Engelberg, $H$. Studies indicating inactivation of post-heparin and endogenous human plasma lipoprotein lipase during triglyceride lipolysis. Proc. Soc. exp. Biol. (N. Y.) 1958, 99, 489.

32. Moreton, J. R. Atherosclerosis and alimentary hyperlipemia. Science 1947, 106, 190.

33. Woldow, A., Chapman, J. E., and Evans, J. M. Fat tolerance in subjects with atherosclerosis: Heparin effects upon lipemia, lipoproteins, and gamma globulin. Amer. Heart J. 1954, 47, 568.

34. Labecki, T. D. Hyperchylomicronemia and hypercholesterolemia: Their correlation with clinical atherosclerosis. Amer. J. clin. Nutr. 1955, 3, 132.

35. Block, W. J., Jr., Mann, F. D., and Barker, N. W. Effect of small doses of heparin in increasing the translucence of plasma during alimentary lipemia : Studies in normal individuals and patients with atherosclerosis. Proc. Mayo Clin. 1951, 26, 246.

36. Angervall, G., and Hood, B. Studies on heparin and lipemia clearing factor. Inhibition towards clearing in plasma from normal and atherosclerotic individuals. Acta med. scand. 1957, 157, 407.

37. Day, A. J., and Wilkinson, G. N. Clearing factor inhibitor in human atherosclerosis. Circulation 1958, 18, 76.

38. Pilgeram, L. O. Deficiencies in the lipoprotein lipase system in atherosclerosis. J. Geront. 1958, 13, 32.

39. Cuttin, J., and Kern, F., Jr. Plasma clearance of induced hyperlipemia in hepatic disease. Clin. Res. 1958, 6, 58.

40. Hall, E. M., Olsen, A. Y., and Davis, F. E. Portal cirrhosis: Clinical and pathologic review of 782 cases from 16,600 necropsies. Amer. J. Path. 1953, 29, 993.

41. Creed, D. L., Baird, W. F., and Fisher, E. R. The severity of aortic arteriosclerosis in certain diseases: A necropsy study. Amer. J. med. Sci. 1955, 230, 385.

42. MacDonald, R. A., and Mallory, G. K. The natural history of postnecrotic cirrhosis: A study of 221 autopsy cases. Amer. J. Med. 1958, 24, 334. 